\title{
Trends
}

\section{The progression of 102 Brazilian patients with bipolar disorder: outcome of first 12 months of prospective follow-up}

\author{
A evolução de 102 pacientes brasileiros com transtorno bipolar: os primeiros \\ 12 meses de acompanhamento prospectivo
}

\author{
Fernanda Novis, ${ }^{1}$ Patricia Cirillo, ${ }^{1}$ Rafael Assis da Silva, ${ }^{1}$ Ana Letícia Santos,${ }^{1}$ Luciana Angélica Silva Silveira, ${ }^{1}$ \\ Adriana Cardoso, ${ }^{1}$ Pedro Coscarelli, ${ }^{2}$ Antônio Egidio Nardi, ${ }^{1}$ Elie Cheniaux ${ }^{3}$
}

\section{Abstract}

Introduction: Prospective studies have shown that the course of bipolar disorder (BD) is characterized by the persistence of symptoms, predominantly depression, along most of the time. However, to our knowledge, no studies in Latin America have investigated it.

Objectives: To replicate international studies using a Brazilian sample to prospectively analyze treatment outcomes in the first year and to determine potential chronicity factors.

Methods: We followed up 102 patients with BD for 12 months and evaluated the number of months with affective episodes and the intensity of manic and depressive symptoms using the Young Mania Rating Scale (YMRS) and the Hamilton Depression Scale (HAM-D17). Sociodemographic and retrospective clinical data were examined to determine possible predictors of outcome.

Results: Almost $50 \%$ of the patients had symptoms about half of the time, and there was a predominance of depressive episodes. Disease duration and number of depressive episodes were predictors of chronicity. Depressive polarity of the first episode and a higher number of depressive episodes predicted the occurrence of new depressive episodes.

Conclusion: In general, BD outcome seems to be poor in the first year of monitoring, despite adequate treatment. There is a predominance of depressive symptoms, and previous depressive episodes are a predictor of new depressive episodes and worse outcome.

Keywords: Clinical progression, outcome assessment, depression, bipolar disorder.

\section{Resumo}

Introdução: Estudos prospectivos vêm demonstrando que o curso do transtorno bipolar (TB) é marcado por uma persistência de sintomas em grande parte do tempo, sendo estes predominantemente depressivos. Porém, até onde sabemos, não há estudos na América Latina sobre o assunto.

Objetivo: Replicar pesquisas internacionais com uma amostra brasileira, para estudar prospectivamente a evolução no primeiro ano de tratamento e possíveis fatores relacionados a cronicidade. Método: Acompanhamos 102 pacientes com TB mensalmente por 12 meses, avaliando o número de meses em episódios afetivos e a intensidade dos sintomas maníacos e depressivos com a Young Mania Rating Scale (YMRS) e a Hamilton Depression Scale (HAM-D17), respectivamente. A partir de dados sociodemográficos e clínicos retrospectivos, buscamos definir fatores preditivos de evolução.

Resultados: Quase metade dos pacientes ficou cerca de metade do tempo sintomática, com predominância de episódios depressivos. Fatores preditivos de cronicidade encontrados foram a duração da doença e o número prévio de episódios depressivos. Encontramos, ainda, como fatores que predizem a ocorrência de novos episódios depressivos, a polaridade depressiva do primeiro episódio e um número maior de episódios depressivos.

Conclusões: Em geral, a evolução do TB é bastante insatisfatória no primeiro ano de acompanhamento, apesar de tratamento adequado, com a predominância de sintomas depressivos. Episódios depressivos prévios são um fator preditivo de novos episódios depressivos e de uma pior evolução.

Descritores: Evolução clínica, avaliação de resultados, depressão, transtorno bipolar.

\footnotetext{
${ }^{1}$ Institute of Psychiatry, Universidade Federal do Rio de Janeiro (UFRJ), Rio de Janeiro, RJ, Brazil. ${ }^{2}$ Universidade do Estado do Rio de Janeiro (UERJ), Rio de Janeiro, RJ, Brazil. ${ }^{3}$ Institute of Psychiatry, UFRJ, Rio de Janeiro, RJ, Brazil. UERJ, Rio de Janeiro, RJ, Brazil.

Financial support: none.

Submitted Sep 10 2012, accepted for publication Jun 09 2013. No conflicts of interest declared concerning the publication of this article.

Suggested citation: Novis F, Cirillo P, da Silva RA, Santos AL, Silva Silveira LA, Cardoso A, et al. The progression of 102 Brazilian patients with bipolar disorder: outcome of first 12 months of prospective follow-up. Trends Psychiatry Psychother. 2013;00(0):000-000. http://dx.doi.org/10.1590/2237-6089-2012-0048
} 


\section{Introduction}

Kraepelin described what we now call bipolar disorder (BD) as a periodic disease with symptom-free intervals and a good outcome. ${ }^{1}$ However, recent studies have suggested that the reality is substantially different. Prospective studies with large samples have shown that $\mathrm{BD}$ is characterized by a chronic course, persistence of symptoms for most of the time ${ }^{2,3}$ and frequent recurrence despite adequate treatment. ${ }^{4}$

Moreover, although the diagnosis is made after a manic episode, ${ }^{5}$ there is a predominance of depressive symptoms along the course of the disease. These symptoms have a subsyndromal intensity most of the times, ${ }^{2}$ which has been associated with the impact that BD has, particularly on occupational and social functioning. ${ }^{6,7}$

Several longitudinal prospective studies have already investigated the course of $\mathrm{BD}^{2,7-9}$ but most included American and European samples, and, to our knowledge, no similar studies have been conducted in Latin America. Therefore, we prospectively evaluated the progression in the first year of follow-up of 102 Brazilian patients with BD in a university outpatient department. The occurrence of affective episodes and the intensity of manic and depressive symptoms were evaluated, as well as the occurrence of psychotic symptoms. At the same time, demographic data and retrospective clinical records were examined to determine possible predictive factors of chronicity. By replicating studies conducted in other continents, this study examined clinical outcomes and predictive factors in a Brazilian sample of patients and compared them to those found in international studies.

\section{Methods}

\section{Sample}

This study, conducted in the BD outpatient research department of the Psychiatry Institute of Universidade Federal do Rio de Janeiro (UFRJ), was approved by the Ethics in Research Committee of that institution on November 23, 2007.

Our BD outpatient research department sees patients referred internally, that is, who had been hospitalized in wards in the same Institute, and externally, who were referred by other services or who sought help directly in our service. The diagnosis of $\mathrm{BD}$ and psychiatric comorbidities is made according to the criteria of the Diagnostic and Statistical Manual of Mental Disorders, 4th edition, Text Revision (DSM-IVTR) ${ }^{5}$ using a semi-structured interview, the Structured Clinical Interview for DSM-IV Axis I Disorders (SCID), ${ }^{10}$ always conducted by the same examiner. Only BD types
I and II are included in outpatient follow-up programs. Other exclusion criteria were: age below 18 years, serious non-psychiatric disease and refusal to sign the consent term. Therefore, patients with psychiatric comorbidities, as well as pregnant and postpartum women, were also included. This study recruited new patients, enrolled in our service from October 2002 to March 2010.

\section{Clinical evaluation}

The patients were treated in a naturalistic followup with monthly visits. Prescribed medications were those dispensed by the Institute's pharmacy whenever possible. A structured open interview was used to collect demographic and retrospective clinical data for each patient: age at onset; time to diagnosis; duration of the disease; number of hospitalizations and previous manic and depressive episodes; psychotic symptoms and psychotic events; polarity of first episode (depression, mania, mixed, psychosis); maternal death before age 11 years; and number of suicide attempts. The following data were separated into categories according to number of events (one, two, three, four, five to nine, ten or more): hospitalizations; depressive, manic and mixed episodes; psychotic events; and suicide attempts. This classification was used because patient recall and reports were inaccurate when there were more than four events.

Every month, each patient was evaluated by the same examiner, the assisting physician, to ensure reliability. Moreover, each physician was previously trained by the senior investigator to use the Young Mania Rating Scale (YMRS) ${ }^{11}$ and the Hamilton Depression Scale (HAM-D17). ${ }^{12}$ However, interexaminer agreement was not evaluated. The number of months with euthymic, manic, depressive and mixed moods was defined according to the DSM-IVTR criteria ${ }^{5}$; manic symptoms were evaluated using the YMRS, ${ }^{11}$ and depressive symptoms, the HAM-D17.12 The mixed state months were conventionally defined as those when the patient had at least two manic symptoms and at least two depressive symptoms. Months of euthymic mood were those when the criteria to define manic and major depressive episodes were not met.

The other outcome measures were intensity of manic and depressive symptoms, according to the monthly application of the YMRS $^{11}$ and the HAM-D17.12 Mean total scores were calculated for the 12 months of followup for each patient. In addition, time free of psychotic symptoms was defined according to clinical observation.

Finally, we studied whether the outcomes of prospective follow-up were associated or correlated with sociodemographic data or clinical history to determine possible predictive factors of chronicity. 
The progression of Brazilian bipolar patients - Novis et al.

\section{Statistical analysis}

The Pearson product-moment correlation was used to analyze continuous variables: age, education, age at onset, time to diagnosis and disease duration. The nonparametric Mann-Whitney $U$ test was used for the comparison between groups according to sex, maternal death before age 11 years and previous psychotic symptoms. The Kruskal-Wallis test, followed by posthoc analyses when an association was detected, compared variables according to multiple categories: marital status; number of manic, depressive and mixed episodes; polarity of first episode; and number of hospitalizations.

A model of generalized linear regression was built for each outcome variable (months with euthymic, manic and depressive moods) and for the scores of manic (YMRS) and depressive (HAM-D17) symptoms. A Poisson distribution was assumed for the outcome variables, and a normal distribution, for symptom scores. The independent variables in each multivariate model were those that had a marginally significant association ( $p \leq$ 0.10 ) in univariate analysis.

The level of significance was set at $p<0.05$ for all the study, with no adjustment for multiple analyses.

\section{Results}

During the study, 102 patients were selected and completed the monthly follow-up during 12 months. Only six had BD type II. A total of 144 patients were excluded because they did not keep regular medical visits.

The sample of excluded patients was characterized by a lower educational level (Mann-Whitney test: $p<$ 0.001 ) than that of the patients that remained in the study. There was a marginally significant difference in age, marital status and hospitalizations: the patients excluded were younger (Mann-Whitney test: $p=0.053$ ), more frequently single (Kruskal-Wallis test: $p=0.087$ ) and had fewer hospitalizations (Kruskal-Wallis test: $p$ $=0.067)$. There were no significant differences in sex, years of schooling, family history, age at onset, diagnosis duration and time to diagnosis.

\section{Sample characteristics and retrospective clinical data}

Table 1 shows the demographic and retrospective clinical data of the 102 patients that completed the 12-month follow-up. Our sample comprised a large number of women, and there was a broad variation in age; the level of education was relatively high, as most patients has at least 11 years of schooling; and less than $50 \%$ of the patients had a partner.
Table 1 - Demographic and retrospective clinical data

\begin{tabular}{|c|c|}
\hline Variable & Results \\
\hline Age, mean \pm standard deviation & $43.36 \pm 12.5$ \\
\hline Women, n (\%) & $70(68.6)$ \\
\hline $\begin{array}{l}\text { Education (years of schooling), } \\
\text { mean } \pm \text { standard deviation }\end{array}$ & $11.56 \pm 3.8$ \\
\hline \multicolumn{2}{|l|}{ Marital status, n (\%) } \\
\hline Single & $34(33.3)$ \\
\hline Married & $37(36.3)$ \\
\hline Divorced/separated & $26(25.5)$ \\
\hline Widowed & $5(4.9)$ \\
\hline Age at onset, mean \pm standard deviation & $25.36 \pm 10.1$ \\
\hline $\begin{array}{l}\text { Time to diagnosis (years), mean } \pm \text { standard } \\
\text { deviation }\end{array}$ & $10.93 \pm 11$ \\
\hline $\begin{array}{l}\text { Disease duration (years), mean } \pm \text { standard } \\
\text { deviation }\end{array}$ & $18.01 \pm 12.8$ \\
\hline \multicolumn{2}{|l|}{ Hospitalizations, n (\%) } \\
\hline 0 & $43(42.2)$ \\
\hline 1 & $18(17.7)$ \\
\hline 2 & $12(11.8)$ \\
\hline 3 & $7(6.9)$ \\
\hline 4 & $6(5.9)$ \\
\hline 5 to 9 & $7(6.9)$ \\
\hline 10 or more & $9(8.8)$ \\
\hline \multicolumn{2}{|l|}{ Manic episodes, n (\%) } \\
\hline 1 & $20(19.6)$ \\
\hline 2 & $15(14.7)$ \\
\hline 3 & $9(8.8)$ \\
\hline 4 & $4(3.9)$ \\
\hline 5 to 9 & $19(18.6)$ \\
\hline 10 or more & $35(34.3)$ \\
\hline \multicolumn{2}{|l|}{ Depressive episodes, n (\%) } \\
\hline 0 & $13(12.7)$ \\
\hline 1 & $19(18.6)$ \\
\hline 2 & $10(9.8)$ \\
\hline 3 & $8(7.8)$ \\
\hline 4 & $5(4.9)$ \\
\hline 5 to 9 & $18(17.6)$ \\
\hline 10 or more & $29(28.4)$ \\
\hline \multicolumn{2}{|l|}{ Pure psychotic episode, n (\%) } \\
\hline 0 & $95(93.1)$ \\
\hline 1 & $1(1)$ \\
\hline 2 & $3(2.9)$ \\
\hline 3 & $0(0)$ \\
\hline 4 & $1(1)$ \\
\hline 5 to 9 & $1(1)$ \\
\hline 10 or more & $1(1)$ \\
\hline
\end{tabular}

Trends Psychiatry Psychother. 2013;XX(X) - X 


\begin{tabular}{lc} 
(cont.) & \\
\hline Polarity of first episode, $\mathrm{n}(\%)$ & $49(48)$ \\
Mania & $53(52)$ \\
Depression & $0(0)$ \\
Mixed mood & $3(2.9)$ \\
Maternal death before age 11 years, $\mathrm{n}(\%)$ & $28(27.5)$ \\
Psychotic symptoms, $\mathrm{n}(\%)$ & \\
Suicide attempts, $\mathrm{n}(\%)$ & $78(76.5)$ \\
0 & $10(9.8)$ \\
1 & $6(5.9)$ \\
2 & $4(3.9)$ \\
3 & $2(2)$ \\
4 & $1(1)$ \\
5 to 9 & $1(1)$ \\
10 or more &
\end{tabular}

Mena age at onset was 25.4 years, and in many cases there was a great time lag between disease onset and diagnosis. Chronicity was an important feature in this sample, as two thirds of the participants had been ill for at least ten years. Most had already had five or more manic episodes, and about $50 \%$ had five or more depressive episodes. Over half had been hospitalized at least once.

The analysis of polarity of first episode revealed that patients were divided practically equally between depression and mania. About one fourth of the patients had already had psychotic symptoms, but only a small percentage had pure psychotic episodes, that is, not concurrent with affective symptoms. Finally, almost one fourth of all participants had already had at least one suicide attempt.

Comorbidities were found in $43.1 \%$ of the patients ( $n=44)$ : obsessive compulsive disorder $(13.7 \% ; n=$ $14)$, social $(12.8 \% ; n=13)$ and specific $(9.8 \% ; n=$ 10) phobias, panic disorder $(9.8 \% ; n=10)$, mostly associated with agoraphobia $(n=7)$, eating disorders $(7.8 \% ; n=8)$, alcohol abuse and dependence (7.8\%; $\mathrm{n}=8$ - abuse: $\mathrm{n}=4$; dependence: $\mathrm{n}=4)$; cocaine abuse and dependence $(5 \% ; n=5$ - abuse: $n=4$; dependence: $\mathrm{n}=2$ ), generalized anxiety disorder $(2.9 \% ; n=3)$, post-traumatic stress disorder $(2.9 \%$; $\mathrm{n}=3)$, epilepsy $(2 \% ; \mathrm{n}=2)$, somatoform disorder $(1 \% ; n=1)$, and conversion disorder $(1 \% ; n=1)$.

Previously taken medication included: lithium (56.9\%; $\mathrm{n}=58$ ) anticonvulsants (valproic acid, carbamazepine, oxcarbazepine, lamotrigine or topiramate) $(78.4 \% ; n=$ $80)$, antidepressants (60.8\%; $\mathrm{n}=62)$, antipsychotics $(76.5 \% ; n=78)$ and benzodiazepines $(69.6 \% ; n=71)$. Nine patients $(8.8 \%)$ had undergone electroconvulsive therapy, and $21.5 \%(n=22)$ had not undergone any previous treatment.

\section{Clinical progression}

The drugs prescribed during the prospective 12-month follow-up were: lithium, 65.7\% ( $\mathrm{n}=$ 67); anticonvulsants (valproic acid, carbamazepine, oxcarbazepine, lamotrigine or topiramate), 67.6\% ( $n=$ $69)$; antidepressants, $41.2 \%(n=42)$; antipsychotics, $77.5 \%(n=79)$; benzodiazepines, $68.6 \%(n=70)$; and thyroid hormone, $9.8 \%(n=10)$. No patient underwent electroconvulsive therapy.

Table 2 shows total time with euthymic, manic and depressive symptoms in the group of 102 patients during the 12-month follow-up, as well as the duration of psychotic symptoms.

Only $5.8 \%(n=6)$ of the participants remained euthymic along all the 12 months, whereas $21.6 \%$ ( $n=$ 22 ) had symptoms during all the study. A total of $43.1 \%$ were symptomatic for at least half of the time. Patients remained euthymic for a mean $4.9 \pm 4.1$ months.

Depressive symptoms were felt at some time by $75.5 \%(n=77)$ of the patients; in $6.9 \%(n=7)$, they occurred for at least half of all the study time. The patients had depressive symptoms for a mean 3.6 \pm 3.5 months.

Manic symptoms were felt by $54.9 \%(n=56)$ of the participants; $6.9 \%(n=7)$ of the patients had manic symptoms at least half of all the study time. No patients had manic symptoms during all the 12 months: mean time with manic symptoms was $1.7 \pm 2.3$ months.

The evaluation of the intensity of the manic symptoms revealed that the mean YMRS ${ }^{11}$ score in the whole sample was $5.2 \pm 4$.3. The mean HAM-D $17^{12}$ score of intensity of depressive symptoms was $6.8 \pm 4.8$.

Mixed moods were found at some time in $49 \%$ ( $n=$ $50)$ of the patients, and $11.8 \%(n=12)$ persisted for at least half of the study time. The patients had a mixed mood for a mean 1.8 \pm 2.6 months.

Psychotic symptoms were found for a mean 1.3 \pm 2.4 months in only $39.2 \%(n=40)$ of the sample. Only seven patients had to be hospitalized, one of them twice. One patient attempted suicide during the prospective 12-month follow-up.

\section{Factors associated with progression}

Total euthymic time during the prospective 12-month follow-up had a negative correlation with total disease duration $(r=-0.23 ; p=0.02)$. In contrast, a greater number of previous depressive episodes was associated with a shorter euthymic time $\left(\chi^{2}=16.24 ; g l=6 ; p=0.01\right)$. In multivariate analysis, only high number of previous depressive episodes was associated with total euthymic time $(p=0.0006)$. 
A longer total depression time in the prospective evaluation was strongly associated with a higher number of previous depressive episodes $\left(\chi^{2}=25.87 ; \mathrm{gl}=6 ; \mathrm{p}=\right.$ $0.002)$ and depressive polarity of the first episode $\left(\chi^{2}=\right.$ $7.44 ; \mathrm{gl}=1 ; \mathrm{p}=0.006)$, as well as with female sex (U test; $p=0.03$ ) and maternal death before age 11 years ( $U$ test; $p=0.04$ ). In multivariate analysis, number of previous depressive episodes $(p<0.0001)$, female sex $(p=0.002)$ and maternal death before age 11 years ( $p$ $=0.005$ ) remained statistically significant.

The intensity of depressive symptoms according to the HAM-D $17^{12}$ scores was positively correlated with total disease duration $(r=0.20 ; p=0.04)$ and negatively correlated with age at onset $(r=-0.21 ; p=0.04)$. Moreover, a higher intensity of depressive symptoms was associated with a greater number of previous depressive episodes $\left(\chi^{2}=13.61 ; \mathrm{gl}=6 ; \mathrm{p}=0.03\right)$ and female sex ( $U$ test; $p=0.01$ ). In multivariate analysis, only number of previous depressive episodes $(p=0.005)$ remained statistically significant.

In univariate analysis, no variables were correlated or associated with total time of manic episodes. Multivariate analysis using variables with marginal significance (marital status and number of previous depressive episodes) revealed that being married $(p=0.0002)$ or divorced ( $p=0.001$ ) had a negative correlation with total manic time (single was the reference category). Greater intensity of manic symptoms according to YMRS $^{11}$ scores was strongly associated with a higher number of previous manic episodes $\left(\chi^{2}=19.48 ; \mathrm{gl}=\right.$ $5 ; \mathrm{p}=0.002)$. As only one variable was statistically significant (including marginal significance), there was no need to conduct a multivariate analysis.

Finally, no variables had any correlation or association with total time in mixed mood or total time of psychotic symptoms.

\section{Discussion}

Our study evaluated the clinical progression of 102 patients with $\mathrm{BD}$ during the first 12 months of their followup in an outpatient research department. Almost half of the patients had affective episodes during most of the time, and about one fifth of the sample had no recovery at any time during the 12 months. The depressive episodes were the most frequent and persistent. About three fourths of the patients had some depressive episode, whereas a little more than half of the sample had some manic episode. Time spent in depression was a mean twice the time in manic or mixed moods. The mean intensity of both depressive and manic symptoms was low, but there were very broad individual variations. In average, psychotic symptoms affected fewer than half of the patients and lasted a shorter period of time.
Table 2 - Clinical progression

\begin{tabular}{|c|c|}
\hline & No. of patients \\
\hline \multicolumn{2}{|c|}{ Total time with euthymic symptoms } \\
\hline$\geq 75 \%$ & 26 \\
\hline$\geq 50 \%$ and $<75 \%$ & 18 \\
\hline$\geq 25 \%$ and $<50 \%$ & 19 \\
\hline$<25 \%$ & 39 \\
\hline \multicolumn{2}{|c|}{ Total time with manic symptoms } \\
\hline$\geq 75 \%$ & 2 \\
\hline$\geq 50 \%$ and $<75 \%$ & 5 \\
\hline$\geq 25 \%$ and $<50 \%$ & 17 \\
\hline$<25 \%$ & 78 \\
\hline \multicolumn{2}{|c|}{ Total time with mixed symptoms } \\
\hline$\geq 75 \%$ & 3 \\
\hline$\geq 50 \%$ and $<75 \%$ & 9 \\
\hline$\geq 25 \%$ and $<50 \%$ & 15 \\
\hline$<25 \%$ & 75 \\
\hline \multicolumn{2}{|c|}{ Total time with depressive symptoms } \\
\hline$\geq 75 \%$ & 14 \\
\hline$\geq 50 \%$ and $<75 \%$ & 12 \\
\hline$\geq 25 \%$ and $<50 \%$ & 28 \\
\hline$<25 \%$ & 48 \\
\hline \multicolumn{2}{|c|}{ Total time with psychotic symptoms } \\
\hline$\geq 75 \%$ & 3 \\
\hline$\geq 50 \%$ and $<75 \%$ & 8 \\
\hline$\geq 25 \%$ and $<50 \%$ & 7 \\
\hline$<25 \%$ & 84 \\
\hline
\end{tabular}

Other authors also found that symptoms persisted for a significant length of the course of the disease..$^{2-4,8,9}$ Judd et al. ${ }^{2}$ prospectively followed up 146 patients with BD type I for 12 to 20 years and found that the patients remained asymptomatic for half of the disease course. Moreover, subsyndromal symptoms were present for a longer time than full affective episodes. Post et al. ${ }^{3}$ followed up 258 patients with BD, most type I, for one year and found that almost half $(40.7 \%)$ of the patients was moderately ill (symptomatic for more than $25 \%$ and less than $75 \%$ of the follow-up time) and more than one fourth were severely ill (symptomatic for more than $75 \%$ of the time). For two years, Perlis et al. ${ }^{4}$ followed up 1,469 patients, who received "the best possible treatment". Despite that, only a little more than half of the sample achieved recovery, and of those who did, almost half had recurrences.

Still in agreement with our findings, the predominance of depressive symptoms over manic and mixed moods along the course of the disease has also been reported in other studies, ${ }^{2,4,8,9}$ and some authors found that psychotic symptoms are not very frequent. ${ }^{2,13}$ In our study, a longer 
time with affective episodes during the prospective 12-month follow-up was correlated with a longer disease duration and associated with a higher number of previous depressive episodes. Total depressive time, in turn, was strongly associated with number of previous depressive episodes, and the occurrence of depressive polarity of first episode; it was also associated with female sex and maternal death before age 11 years. Longer disease duration, lower age at onset, more previous depressive episodes, depressive polarity of first episode and female sex were predictive of more intense depressive symptoms. Total manic time was not correlated or associated with any sociodemographic or retrospective clinical data, which may be explained by the fact that our patients had a shorter percentage of manic time. However, a greater number of previous manic episodes was strongly predictive of more severe manic symptoms during the prospective 12-month follow-up. Total time of psychotic symptoms was also not correlated with any variable, possibly because psychotic symptoms were observed for only a short time.

Several outcome factors found in our study have also been reported by other authors: number of previous affective episodes, ${ }^{3,14,15}$ depressive polarity of first episode, ${ }^{2,16,17}$ female sex, ${ }^{18-20}$ disease duration ${ }^{20}$ and early onset.17,21,22 Other authors have suggested that previous depressive episodes might predict a progression with more depressive symptoms, whereas previous manic episodes might predict a progression with more manic symptoms. In this sense, Nolen et al. ${ }^{14}$ found that a greater intensity of depressive and manic symptoms is associated with a high number of previous depressive and manic episodes. Daban et al., ${ }^{17}$ however, found that, in agreement with our findings, depressive polarity of first episode was a good predictor of greater chronicity and of predominance of depressive polarity of subsequent episodes.

Therefore, greater attention has been drawn to the theory created by Angst, $^{23}$ of a polarity predominance in patients with BD. ${ }^{24-26}$ According to that theory, some patients tend to have twice or more manic than depressive episodes, whereas the opposite is true for some other patients. Such type of predominance seems to be found in about half of the patients with BD. ${ }^{24}$ Still according to that theory, the predominance of depressive episodes is more frequent than that of manic episodes ${ }^{25,26}$ and is be associated with poorer outcomes. ${ }^{24-26}$

Differently from other studies, we did not find any correlation between outcome and psychotic symptoms ${ }^{4,15,16,27-30}$ or number of previous hospitalizations. ${ }^{31,32}$ However, contradictions about which factors predict outcomes are frequent in the literature. ${ }^{13-15,31,33}$ The major reason of this inconsistency has been linked to method differences, ${ }^{34}$ as there are different criteria to define a poor outcome, such as total symptomatic time, time to recurrence and others.

One of the limitations of our study was the severity of patient disease, as they were followed up in a BD outpatient research department. Therefore, our sample may fail to represent all individuals that have BD. In our outpatient research department, we see seriously affected patients referred by other institutions, as well as patients referred directly after hospitalization. In contrast, a large number of the patients under treatment were excluded from the sample because they did not keep the monthly attendance to visits during the study time. We believe that some of them were patients with more severe disease. Therefore, as this sample excluded a large number of patients that were not able to keep their regular follow-up, the patients selected may not represent the population of interest, a fact that may affect the internal validity of this study. Moreover, the patients excluded from the study had a lower socioeconomic status than those that were included, which may complicate the generalization of our study findings for this population.

Another limitation was the fact that it was a naturalistic investigation and the follow-up time, only 12 months, was short. However, other longitudinal studies that conducted evaluations of up to 20 years ${ }^{2,3,8,9}$ reported similar results, which confirms certain constancy along time. Finally, the sample was very heterogeneous, and there were great variations in retrospective clinical data (age, age at onset, time to diagnosis and disease duration). This may have interfered with the adequate evaluation of factors that predicted outcome, which indicates that studies should separate participants into more homogenous groups and conduct more careful analyses of the interference of individual factors.

Moreover, numerous participants had been ill for a long time and might have experienced several different approaches to treatment, which may determine poorer patient progression than more recent disease and more adequate treatment approaches.

\section{Conclusion}

In agreement with other studies, our findings showed that BD outcomes seem to be poor, even when the patients are followed up in research centers and comply with treatment adequately. A large percentage of patients had affective episodes, particularly depressive events in most of the time. We also found that disease duration and previous number of depressive episodes are factors that predict a poor prognosis. Finally, our results confirm findings that depressive polarity of first episode 
and higher number of previous depressive episodes predict the occurrence of new depressive episodes and their greater intensity. Therefore, more effective BD treatments should be developed, particularly for the management of depressive episodes, as they seem to have a greater impact on outcome. In the same line, we plan future studies to investigate the occurrence of polarity predominance during the course of the disease and to evaluate factors that predict outcome in subgroups according to retrospective clinical differences.

\section{References}

1. Kraepelin E. Dementia praecox and manic-depressive insanity. New York: The Classics of Psychiatry and Behavioural Sciences Library; 1989.

2. Judd LL, Akiskal HS, Schettler PJ, Endicott J, Maser J, Solomon DA, et al. The long-term natural history of the weekly symptomatic status of bipolar I disorder. Arch Gen Psychiatry. 2002;59:530-7.

3. Post RM, Denicoff KD, Leverich GS, Altshuler LL, Frye MA, Suppes TM, et al. Morbidity in 258 bipolar outpatients followed for 1 year with daily prospective ratings on the NIMH life chart method. J Clin Psychiatry. 2003;64:680-90.

4. Perlis $\mathrm{RH}$, Ostacher $\mathrm{MJ}$, Patel JK, Marangell LB, Zhang $\mathrm{H}$, Wisniewski SR, et al. Predictors of recurrence in bipolar disorder: primary outcomes from the systematic treatment enhancement program for bipolar disorder (STEP-BD). Am J Psychiatry. 2006; 163:217-24.

5. American Psychiatric Association. Diagnostic and Statistical Manual of Mental Disorders - 4th edition (DSM-IV): Primary Care Version. Washington: APA; 1995.

6. Altshuler LL, Post RM, Black DO, Keck PE Jr, Nolen WA, Frye MA et al. Subsyndromal depressive symptoms are associated with functional impairment in patients with bipolar disorder: results of a large, multisite study. J Clin Psychiatry. 2006;67:1551-60.

7. Marangell LB, Dennehy EB, Miyahara S, Wisniewski SR, Bauer MS, Rapaport $\mathrm{MH}$, et al. The functional impact of subsyndromal depressive symptoms in bipolar disorder: data from STEP-BD. J Affect Disord. 2009;114:58-67.

8. Joffe RT, MacQueen GM, Marriott M, Trevor Young L. A prospective longitudinal study of percentage of time spent ill in patients with bipolar I or bipolar II disorders. Bipolar Disord. 2004;6:62-6.

9. Miller IW, Uebelacker LA, Keitner GI, Ryan CE, Solomon DA. Longitudinal course of bipolar I disorder. Compr Psychiatry. 2004; 45:431-40.

10. First MB, Spitzer RL, Gibbon M, Williams JB. Structured Clinical Interview for DSM-IV Axis I Disorders: Clinician Version. Washington: American Psychiatric Press; 1997.

11. Young RC, Biggs JT, Ziegler VE, Meyer DA. A rating scale for mania: reliability, validity and sensitivity. Br J Psychiatry. 1978;133:429-35.

12. Hamilton M. A rating scale for depression. J Neurol Neurosurg Psychiatry. 1960;23:56-62.

13. Keck PE Jr, McElroy SL, Havens JR, Altshuler LL, Nolen WA, Frye $M A$, et al. Psychosis in bipolar disorder: phenomenology and impact on morbidity and course of illness. Compr Psychiatry. 2003;44:263-9.

14. Nolen WA, Luckenbaugh DA, Altshuler LL, Suppes T, McElroy $\mathrm{SL}$, Frye MA, et al. Correlates of 1-year prospective outcome in bipolar disorder: results from the Stanley foundation bipolar network. Am J Psychiatry. 2004;161:1447-54.

15. Turvey CL, Coryell WH, Solomon DA, Leon AC, Endicott J, Keller $\mathrm{MR}$, et al. Long-term prognosis of bipolar I disorder. Acta Psychiatr Scand. 1999;99:110-9.

16. Frangou S. Predictors of outcome in a representative population of bipolar disorder. Bipolar Disord. 2002;4(Suppl 1):41-2.
17. Daban C, Colom F, Sanchez-Moreno J, García-Amador M, Vieta E. Clinical correlates of first-episode polarity in bipolar disorder. Compr Psychiatry. 2006;47:433-7.

18. Altshuler LL, Kupka RW, Hellemann G, Frye MA, Sugar CA McElroy SL, et al. Gender and depressive symptoms in 711 patients with bipolar disorder evaluated prospectively in the Stanley Foundation bipolar treatment outcome network. Am J Psychiatry. 2010;167:708-15.

19. Robb JC, Young LT, Cooke RG, Joffe RT. Gender differences in patients with bipolar disorder influence outcome in the medical outcomes survey (SF-20) subscale scores. J Affect Disord. 1998;49:189-93.

20. Mander AJ. Clinical prediction of outcome and lithium response in bipolar affective disorder. J Affect Disord. 1986;11:35-41.

21. Yatham LN, Kauer-Sant'Anna M, Bond DJ, Lam RW, Torres I. Course and outcome after the first manic episode in patients with bipolar disorder: prospective 12-month data from the Systematic Treatment Optimization Program For Early Mania project. Can J Psychiatry. 2009;54:105-12.

22. Benazzi F. Classifying mood disorders by age-at-onset instead polarity. Prog Neuropsychopharmacol Biol Psychiatry. 2009; 33:86-93.

23. Angst $\mathrm{J}$. The course of affective disorders. II. Typology of bipolar manic depressive illness. Arch Psychiatr Nervenkr. 1978;226:65-73.

24. Colom F, Vieta E, Daban C, Pacchiarotti I, Sánchez-Moreno J. Clinical and therapeutic implications of predominant polarity in bipolar disorder. J Affect Disord. 2006;93:13-7.

25. Rosa AR, Andreazza AC, Kunz M, Gomes F, Santin A, SanchezMoreno J, et al. Predominant polarity in bipolar disorder: diagnostic implications. J Affect Disord. 2008;107:45-51.

26. Vieta $E$, Berk M, Wang W, Colom F, Tohen M, Baldessarini RJ. Predominant previous polarity as an outcome predictor in a controlled treatment trial for depression in bipolar I disorder patients. J Affect Disord. 2009;119:22-7.

27. Tohen M, Waternaux CM, Tsuang MT. Outcome in mania. A 4-year prospective follow-up of 75 patients utilizing survival analysis. Arch Gen Psychiatry. 1990;47:1106-11.

28. Winokur G, Scharfetter C, Angst J. A family study of psychotic symptomatology in schizophrenia, schizoaffective disorder, unipolar depression, and bipolar disorder. Eur Arch Psychiatry Neurol Sci. 1985;234:295-8.

29. Rosen LN, Rosenthal NE, Dunner DL, Fieve RR Social outcome compared in psychotic and nonpsychotic bipolar I patients. J Nerv Ment Dis. 1983:171: 272-5.

30. Rosenthal NE, Rosenthal LN, Stallone F, Fleiss J, Dunner DL, Fieve RR. Psychosis as a predictor of response to lithium maintenance treatment in bipolar affective-disorder. J Affect Disord. 1979;1:237-45.

31. González-Isasi A, Echeburúa E, Limiñana JM, González-Pinto A. Predictors of good outcome in patients with refractory bipolar disorder after a drug or a drug and cognitive-behavioral treatment. Compr Psychiatry. 2012;53:224-9.

32. Rosa AR, Reinares M, Franco C, Comes M, Torrent C, SánchezMoreno J, et al. Clinical predictors of functional outcome of bipolar patients in remission. Bipolar Disord. 2009;11:401-9.

33. MacQueen GM, Young LT, Joffe RT. A review of psychosocial outcome in patients with bipolar disorder. Acta Psychiatr Scand. 2001; 103:163-70.

34. Keck PE Jr, McElroy SL, Strakowski SM, West SA, Sax KW, Hawkins JM, et al. 12-month outcome of patients with bipolar disorder following hospitalization for a manic or mixed episode. Am J Psychiatry. 1998;155:646-52.

\section{Correspondence:}

Fernanda Novis

Av. das Américas, 3333, sala 410, Barra da Tijuca

22631-003 - Rio de Janeiro, RJ - Brazil

Tel./Fax: +55-21-2497-3435

E-mail: novisfernanda@gmail.com 